\title{
INVESTIGACIÓN/RESEARCH
}

\section{LA EVOLUCIÓN ESTRATÉGICA DE LA PRENSA ESPECIALIZADA EN LA HISTORIA DEL PERIODISMO. UN ESTUDIO DE CASO}

\author{
María Verónica de Haro-de San Mateo ${ }^{1}$ : Universidad de Murcia. España \\ mvdeharo@um.es
}

\section{RESUMEN}

El nacimiento y posterior asentamiento de los nuevos soportes informativos ha obligado a la prensa escrita a practicar un ejercicio de continua adaptación a lo largo de su historia. Gracias a esta práctica, la prensa editada en papel ha logrado llegar a nuestros días. En este artículo se pone de relieve un estudio de caso, el de la evolución estratégica de la revista especializada 6TOROS6, que acaba de cumplir sus primeras dos décadas de vida, ante el éxito de los portales de información taurina en Internet.

PALABRAS ClAVE: Prensa especializada - Internet- 6TOROS6 - Historia del Periodismo.

\section{THE STRATEGIC EVOLUTION OF THE SPECIALIZED PRESS IN THE HISTORY OF THE JOURNALISM. A CASE STUDY}

\section{ABSTRACT}

The establishment of the new mass media has forced to the printed press to practice an exercise of continuous adjustment throughout its history. Thanks to this practice, the printed press has made it to this day. This article examines the strategic evolution of the specialized magazine 6TOROS6, that has just expired its first two decades of life, given the success of the webs about bullfighting information.

KEY WORDS: Specialized press - Internet - 6TOROS6 - History of J ournalism

\footnotetext{
${ }^{1}$ Autor Correspondiente

María Verónica de Haro-de San Mateo: Profesora de la Universidad de Murcia. España. España.

Correo: mvdeharo@um.es
} 


\section{INTRODUCCIÓN}

La máxima de la prensa a lo largo de su historia ha sido "evolucionar o morir". Ciertamente, el nacimiento y posterior asentamiento de los nuevos soportes informativos (la radio y la televisión primero y últimamente Internet) ha obligado a la prensa a practicar un ejercicio de continua adaptación gracias al cual ha logrado llegar a nuestros días. Por su parte, las distintas especialidades del periodismo están presentes en todos los soportes informativos y responden, como bien señala Concha Edo (1999), a la urgencia que tienen los lectores, los radioyentes y los telespectadores de asimilar los cambios culturales, científicos, económicos, sociales y políticos que tuvieron lugar en el siglo XX. Entre todos los existentes, el sector estrella de la especialización, el que brinda la oferta más amplia y variada en cuanto a temas, niveles de divulgación, periodicidad, precios y presentación de la información es, sin lugar a dudas, el de las revistas. En este campo, la prensa especializada no ha sido la excepción en la línea evolutiva que apuntamos. Este artículo pone de relieve un estudio de caso, el de la evolución estratégica de la revista especializada 6TOROS6 tras el éxito de los portales de información taurina en Internet.

6TOROS6 nace en abril de 1991 como revista mensual de información taurina y llega a nuestros días como un semanario consolidado y de absoluta referencia en el panorama periodístico taurino. En sus primeros veinte años de vida ha logrado varios hitos, no sólo de la historia de esta especialidad periodística sino también del conjunto de la historia del periodismo español. Entre otros, convertirse en la primera publicación de este país que se edita, durante un tiempo, también en francés ${ }^{2}$ y ser la pionera en intentar una edición internacional para México ${ }^{3}$ - hecho que posibilita primero el acercamiento de los países taurinos de ambos lados del Atlántico y a la postre que 6TOROS6 sea el medio con mayor presencia en el planeta de los toros - .

Otra de sus conquistas, quizá la más importante porque supone un verdadero punto de inflexión en la vida de la publicación y en el conjunto de la prensa taurina especializada, es haber sido la primera revista de toros capaz de ofrecer, en el número que sale a la venta los martes, la crónica y las imágenes de los festejos más relevantes celebrados en cualquier parte del mundo hasta el domingo inmediatamente anterior a su venta en los kioscos ${ }^{4}$.

\footnotetext{
${ }^{2}$ La implantación en Francia - país cuya programación de espectáculos representa aproximadamente el $25 \%$ del mercado taurino - es una necesidad para cualquier medio taurino que se precie. Lo es para 6TOROS6 desde su inicio aunque esta idea acaba por materializarse en marzo de 1993. La edición francesa aparece con carácter mensual al igual que su homóloga española pero sale a la venta unos días más tarde que ésta. La traducción de los textos y el reajuste de la maqueta requieren, lógicamente, un tiempo extra. El alto trabajo que supone su elaboración y una rentabilidad siempre límite - difícil en los meses de invierno - son las causas de que este proyecto no llegue a consolidarse, tampoco como bimensual, y acabe desapareciendo durante la temporada del año 1995

${ }^{3}$ El seis de diciembre de 1994 se produce en México un hecho feliz en la historia de la revista 6TOROS6: el nacimiento de su edición internacional. Lamentablemente ésta tendrá una vida efímera pues desaparece apenas cuatro meses después

${ }^{4}$ El primer número de 6TOROS6 en el que esto ocurre es el 57 (28 de marzo de 1995) cuando la revista tiene todavía una frecuencia quincenal. 6 TOROS6 se edita semanalmente a partir del número 60 (9 de mayo de 1995)
} 
La aceptación alcanzada por 6TOROS6 entre los aficionados a la Fiesta y los profesionales del sector se debe a la suma de varios factores. El primero es que, desde su nacimiento, ha sido fiel reflejo de su presente taurino y desde que conquista la frecuencia semanal ese acercamiento a la actualidad se ha hecho más patente. El segundo es que, pese a lo anterior, no ha descuidado el empeño analítico innato a cualquier publicación especializada pudiendo afirmarse que su afán por contextualizar y jerarquizar el presente taurino es constante desde su inicio. El tercero abunda en la idea de universalidad de la revista, concepto que le ha llevado a cubrir informativamente no sólo la actualidad derivada de la Fiesta en España sino en todos los países donde la Tauromaquia existe ${ }^{5}$. El cuarto es que aun siendo una revista de actualidad taurina, no se centra única y exclusivamente en lo sucedido en los ruedos sino que ofrece al lector, entre otros, numerosos trabajos de carácter histórico y cultural en torno al planeta de los toros que confieren a la publicación gran poso y relevancia. Tanto es así que algunas de estas secciones se han convertido posteriormente en libros que son verdaderos tratados de Tauromaquia ${ }^{6}$. El quinto es por todo lo apuntado hasta ahora - su calidad en el fondo y en la forma, al tratarse de la primera revista taurina editada completamente a color en un papel de tanta calidad $^{7}$

\section{METODOLOGÍA}

El presente trabajo empleo el método histórico lógico para realizar una valoración de la vida de las revistas Toros` 92 y el Toreo. Este artículo pretende describir la historia y propósito de ambas incidiendo en aquellos aspectos que más tarde son característicos de 6Toros6.

Para ilustrar un mejor análisis se realizó una clasificación por momentos históricos respect0 a su desempeño con el surgimiento del Internet. Este estudio cualitativo permitió caracterizar la evolución estratégica de la revista especializada 6TOROS6, que acaba de cumplir sus primeras dos décadas de vida, ante el éxito de los portales de información taurina en Internet.

\footnotetext{
${ }^{5}$ Los países en los que actualmente tiene vigencia la Tauromaquia son: España, Francia, Portugal, México, Colombia, Venezuela, Perú y Ecuador. De modo anecdótico la revista también ha estado presente en algunos escenarios en los que se han celebrado festejos taurinos como EE.UU., China, Japón, Armenia y Egipto

${ }^{6}$ Algunas de las secciones que posteriormente se han editado en formato libro son "Las suertes del toreo", "Toromaquia" y "Figuras del siglo XX". Véanse los libros: RAMÓN CARRIÓN, José Luis (1998): Todas las suertes por sus maestros. Espasa Calpe. Madrid; ORTIZ, Santiago (1999): El arte de ver toros, una tauromaquia educativa. Espasa Calpe. Madrid; AGUADO, Paco

${ }^{7}$ Desde su inicio 6TOROS6 alberga varios pliegos a color, generalmente los que contienen las cubiertas, los principales trabajos de cada número y las páginas publicitarias. A medida que la revista se consolida en el mercado crece el número de estos pliegos hasta que en octubre de 1995, concretamente el número 81 de 6TOROS6, es editado completamente a color
} 


\section{ANÁLISIS Y DISCUSIÓN}

\subsection{TOROS6, antes y después de Internet}

A comienzos de la década de los noventa, el periodismo taurino en la prensa diaria tiene una calidad informativa y una presencia considerables. Vicente Zabala en la tribuna de ABC, Javier Villán en El Mundo, "Barquerito" en Diario 16 y J oaquín Vidal en El País firman las crónicas de las ferias taurinas más importantes. Entre la prensa de provincias encontramos abundantes ejemplos de cabeceras que cubren informativamente la temporada taurina. Es el caso de El Correo de Andalucía, La Tribuna de Salamanca o La Verdad. En radio sobresalen los programas taurinos "Clarín" de RNE, "El Albero" de COPE y "Los Toros" de Cadena SER. En cuanto a la televisión, el ente público retransmite abundantes festejos y mantiene el programa "Tendido Cero" dirigido por Fernando Fernández Román, mientras que en las cadenas autonómicas y privadas como Telemadrid o Canal Plus, la Fiesta es objeto de un notable interés ${ }^{8}$.

En este contexto, 6TOROS6 ve la luz por primera vez iniciada la temporada taurina de 1991. El formato, moderno a la vista y agradable al tacto, debe sorprender y agradar a los aficionados. El estupendo papel en el que está impresa y su atractivo diseño llaman verdaderamente la atención. La prensa taurina de la época no acostumbra tantos lujos ${ }^{9}$. No obstante, pese a los vistosos resultados, la revista se confecciona con los escasos medios técnicos de principios de los noventa. El proceso de edición es lento, imperfecto y costoso porque está, igual que la propia impresión, totalmente externalizado.

En estos primeros momentos, la revista se diseña a lápiz y con ayuda del tipómetro y su mayor ocupación es ofrecer un concienzudo análisis de la realidad taurina contemporánea en contraposición al puntual seguimiento informativo ofrecido por el resto de los medios. Su periodicidad - primero mensual y posteriormente quincenal -

\footnotetext{
${ }^{8}$ Para ampliar información sobre la presencia de información taurina en los medios de comunicación en España véase: de Haro de San Mateo, Ma Verónica (2009c): “Un ejemplo de realidad fragmentada: la información taurina en los medios de comunicación españoles", en Revista Vivat Academia, no 109, 2009. [ www.ucm.es/info/vivataca/numeros/n109/articulo.htm\#unejem Fecha de consulta: 20 de marzo de 2010]

${ }^{9}$ La única publicación taurina española y comercial que, en este momento, acude puntualmente a su cita con el lector para informar sobre el mundo de los toros es Aplausos, la revista que en 1976 funda Salvador Pascual, una publicación editada en blanco y negro que luce un diseño arcaico si se la compara con el que ofrece, incluso en sus comienzos, 6TOROS6. Desde 1989 se venía editando la revista cultural taurina Taurología, una revista lujosamente impresa que, a diferencia 6TOROS6, no muestra interés por la actualidad del mundo de los toros y que curiosamente, muere en el mes que nace la revista que nos ocupa. Para más información sobre Taurología, véanse: ROMERO DE SOLÍS, Pedro (2000): "Las revistas culturales de toros en España: Taurología" en Revista de Estudios Taurinos, no 12, 2000. Pp. 173-264 y DE HARO DE SAN MATEO, Ma Verónica (2004): "Taurología, referente de las revistas culturales taurinas" en SANZ ESTABLÉS, Carlos; SOTELO GONZÁLEZ, Joaquín; RUBIO MORAGA, Ángel Luis (coords.) Prensa y Periodismo Especializado II, Actas del II Congreso de Prensa y Periodismo Especializado (pp. 401-410). Editores del Henares. Guadalajara.
} 
la oferta informativa taurina del panorama mediático del momento condicionan el hecho de que la revista se dedique a este menester.

En febrero de 1994 comienza una nueva etapa de crecimiento para 6TOROS6 que coincide con el cambio de propiedad de la revista ${ }^{10}$. La intensa renovación tecnológica que se acomete posibilita la edición de una publicación mucho más moderna ${ }^{11}$ y plegada a la actualidad que la de la etapa precedente y el paso, un año después, a semanal.

6TOROS6 es una de las primeras revistas españolas que incorporan Internet al proceso informativo. Este hecho agiliza muy sustancialmente el envío de información, sobre todo el material gráfico, lo que acaba posibilitando un incremento de la cantidad y la calidad de las fotografías publicadas en la revista. En este sentido, es muy ilustrativa la descripción del director de la publicación, José Carlos Arévalo, sobre el modo en que llegaban los carretes de fotos a la redacción en los primeros tiempos. Evidentemente, la crónica se podía dictar por teléfono, pero las fotos - con un servicio postal que no trabajaba entonces como ahora, ni domingos ni festivos y sin las posibilidades que poco después brindaría Internet - era muy difícil enviarlas a tiempo para su publicación:

Cuando terminaba una corrida, los carretes viajaban en los coches de cuadrillas y, a su paso por Madrid, los dejaban en la recepción del Hotel Reina Victoria. A nosotros nos venía estupendamente porque la redacción de la revista siempre ha estado muy cerquita de este taurinísimo hotel. Por aquel entonces, nosotros teníamos un laboratorio de revelado muy pequeñito que en ocasiones no daba abasto. Entonces también recurríamos a los VIPS, unos establecimientos que para nosotros han supuesto un servicio impagable porque nos permitían revelar hasta las doce de la noche. Así se explica que en los primeros tiempos de 6TOROS6 no aparezcan fotografías de los festejos celebrados los domingos fuera de Madrid. Desde el punto de vista de la edición, aunque ese proceso tenía su encanto, la revista era menos solvente que ahora. Se puede decir que estábamos, en la parte gráfica, menos plegados a la actualidad que ahora" (De Haro, 2009, pp. 72-73)

José Luis Ramón, redactor jefe de la publicación en esos momentos y actual director adjunto de 6TOROS6, abunda en la anécdota anterior para referirse a la evolución del proceso de edición experimentado por la revista en todo este tiempo:

Imagínate lo que era depender del correo para confeccionar una revista como

\footnotetext{
${ }^{10}$ 6TOROS6 es editada inicialmente por Ediciones Abenamar, una sociedad empresarial encabezada por el conocido empresario

${ }^{11}$ A partir de ese momento se produce la auto edición con ordenadores propios y Word Perfect versión 5.1. Un año después se diseña ya con Macintosh. La fotomecánica se incorpora en marzo de 1996 y el fotolito de capacidad justo a comienzos del año siguiente. Esto se traduce en más pliegos a color y un diseño mucho más moderno, gracias a las mayores posibilidades de edición.
} 
ésta en la que el material gráfico es fundamental. Antes tampoco existían las cámaras de fotos digitales y los fotógrafos debían revelar los carretes antes de enviar las copias a la redacción y por eso el tiempo que necesitaba todo el proceso era mucho mayor. Si a ello añadimos que aquí se trabaja con sistema de cierres durante toda la semana, podrás comprender lo diferente que era todo. Las fotografías que ilustran las crónicas y los temas nos llegaban a través de SEUR. EI servicio "SEUR 10" era utilizadísimo. Antes nos enviaban las imágenes en entregas. Por ejemplo, para el cierre de los jueves nos enviaban todas las imágenes de acontecimientos celebrados hasta el miércoles a mediodía.

Los viernes por la mañana nos llegaban las imágenes del miércoles tarde y jueves. Y el domingo nos llegaban las del viernes y sábado. Hace unos años no dábamos imágenes de los festejos del domingo, precisamente porque no hay correo postal. Es muy interesante el modo en que aquí llegaban los materiales. Usábamos, menos la paloma mensajera, casi todos los medios para que nos llegaran fotos: los coches de cuadrillas, los mozos de espadas y hasta algún subalterno servía de porteador. El Hotel Reina Victoria era el depósito de todo esto. Luego íbamos, lo recogíamos y, a toda prisa, escaneábamos las fotos, componíamos las páginas de crónicas, publicidad y cerrábamos para la imprenta los pliegos que tocaran. Todo esto con Internet ha cambiado. Ahora todos los fotógrafos tienen cámara digital, ordenador y correo electrónico y nos envían a través de él las imágenes. Es mucho más rápido todo. I gual sucede con los textos, pues los corresponsales después de la corrida, escriben su crónica y desde su casa, el hotel o desde un ciber-café envían su trabajo sin mayor problema. Por no hablar de los cierres de invierno con información de las corridas celebradas el mismo domingo en las plazas americanas. Nunca antes una revista taurina semanal había podido, porque la tecnología no lo permitía, incluir fotos de cinco o seis plazas americanas en el cierre del domingo. Internet lo que ha hecho ha sido universalizar todo esto Indudablemente nos ha favorecido (De Haro, 2009, pp. 73-74).

En verdad, la implantación de las nuevas tecnologías al proceso de edición y la temprana incorporación de Internet suponen una auténtica revolución en la vida de 6TOROS6. La primera es el salto a la periodicidad semanal. Desde mayo de 1995, el aficionado puede disfrutar cada martes en las páginas de esta revista, de las crónicas y las imágenes de los festejos taurinos más relevantes celebrados incluso durante la madrugada del lunes (hora española) en cualquier ruedo de cualquier país. A partir de ese año 6TOROS6 crece cualitativamente y comienza a consolidarse en el mercado.

La publicación experimenta un formidable desarrollo y, sin dejar de profundizar en los temas, reflexionando y analizando la realidad taurina, aborda exhaustivamente la actualidad del planeta de los toros con frecuencia semanal ${ }^{12}$. La revista acomete una

\footnotetext{
${ }^{12}$ El paso a la periodicidad semanal conlleva un mayor ritmo de trabajo. Por este motivo aumenta el número de corresponsales y se refuerza la redacción central en Madrid con la incorporación de varios redactores.
} 
labor notarial para contrarrestar la cada vez más escueta información tauromáquica ofrecida por la prensa diaria. Editorial Campo Bravo S.L. ${ }^{13}$ es la tercera sociedad editora en la vida de 6TOROS6, la que por fin posibilita su pleno desarrollo y consolidación permitiendo que sea en la actualidad el medio especializado en información taurina con mayor presencia en todo el planeta de los toros.

\subsection{La competencia de los portales taurinos en Internet para 6TOROS6}

Un análisis más profundo de la relación entre la revista y la herramienta Internet nos obliga a describir el modo en que 6TOROS6 ha asumido la competencia directa de los portales taurinos especialmente www.burladero.com ${ }^{14}$, el portal de información taurina en Internet líder del panorama mediático.

Cuando nace www.burladero.com, la publicación objeto de nuestro estudio lleva casi diez temporadas acudiendo a su cita con los lectores a pie de kiosco. Muy probablemente porque acaba de asentarse en el mercado, los editores de la revista recelan del fulgurante éxito del portal a los pocos meses de nacer. Paco Aguado, director adjunto de 6TOROS6 en esos momentos, escribía a propósito de la presencia taurina en el nuevo soporte informativo unos pocos meses después de aparecer el portal dirigido por Miguel Ángel Moncholi, en estos términos:

Cada vez son más los frentes en donde ha de batirse el cobre de la información taurina, en muchos de los cuales no siempre existe claridad suficiente como para sacar conclusiones que transmitirle al aficionado. Nada es blanco ni negro, todo son matices de gris que conviene relativizar y meditar antes de opinar con suficiente fundamento. Pero los tiempos han cambiado y ya no hay lugar para la calma. Urge la información primera, la exclusiva, y los periodistas nos dejamos llevar por la espiral de la prisa sin detenernos a mirar a los lados, sin pararnos a pensar a qué y a quiénes servimos como intermediarios de esta ceremonia de la confusión. $Y$ de esta forma reflejamos en nuestro abundante trabajo toda esta locura coyuntural. Atendemos y transmitimos más noticias que nunca y apabullamos con ellas a un oyente y a un lector que, en cambio, se siente más confuso que nunca, sin sacar una idea clara del revuelto río del espectáculo taurino. Radios, periódicos, revistas, televisiones, gacetas de peñas, Internet ahora... cada vez existe un mayor acceso a la información taurina, pero a la vez que eso sucede va desapareciendo el análisis paciente, la necesaria

${ }^{13}$ Editorial Campo Bravo, S. L., según figura en el Registro Mercantil Central, se constituye en sociedad limitada con propósito de duración indefinida el 27 de octubre de 1998 fijando su domicilio social en el número 6 de la madrileña calle Mayor. La edición de todo tipo de publicaciones, la realización de trabajos de artes gráficas, publicidad, marketing, diseño, identidad corporativa y comunicación integral constituye el grueso de su objeto social. Jorge Efrén Martínez Lambarry es su administrador único y José Carlos Arévalo Díaz de Quijano figura como apoderado. En México la revista está editada por Campo Bravo S.A., de capital variable. Ambas empresas pertenecen al grupo empresarial Pastejé presidido por el industrial Carlos Peralta

${ }^{14}$ Para más información sobre el portal www.burladero.com véase: MONCHOLI CHAPARRO, Miguel Ángel (2003): Burladero.com, la aventura de los toros en Internet. Egartorre. Madrid. 
cordura con que se puede y se debe meditar el toreo (Aguado, 2000, p. 4)

La "última hora" del mundo de los toros se publica con una velocidad asombrosa en el más moderno de los medios, un soporte que todavía no ofrece ni audio ni imágenes en movimiento como lo hará poco tiempo después. Muy probablemente por esta razón, la revista emprende una táctica inteligente, reforzar aquellos trabajos que le diferencian de este exitoso pero efímero medio. En líneas generales se puede afirmar que el interés por informar y opinar a propósito de la realidad taurina sigue vigente en 6TOROS6 aunque la fórmula que la publicación adopta para sobrevivir el nacimiento y éxito de los portales taurinos en Internet es la de intensificar la tarea analítica del presente taurino, consciente de que la última hora, la información de más estricta actualidad, ha encontrado un soporte ideal, la Red.

Paco Aguado abunda en esta idea a propósito del rediseño de 6TOROS6 en marzo de 2008. La sensible renovación en la presentación de los contenidos y el nacimiento de nuevas secciones responden a la necesidad de adaptarse a los tiempos. Aguado lo explica así, curiosamente, en el portal www.burladero.com:

La irrupción de los portales taurinos ha traído consigo una tremenda inmediatez a la hora de dar la información. Una inmediatez con la que desde una revista semanal como la nuestra no podemos competir. Por eso, vamos a seguir ahondando y profundizando en el análisis y la opinión de todo cuanto vaya deparando la temporada. Esto no quiere decir que despreciemos la información, que por supuesto seguirá teniendo un espacio destacado. La actualidad manda, pero no queremos ser esclavos de la prisa, que considero es una de las grandes enemigas del periodismo actual (Aguado, 2008, p. 8)

Por su parte, el director de 6TOROS6 sostiene que pese a la aparición de este nuevo soporte, la revista no abandona la información de los hechos más sobresalientes por su afán notarial:

6TOROS6, en estos momentos y pese a los últimos cambios, no es la revista que nosotros queremos hacer, es la revista que estamos obligados a hacer, porque como los medios de información general no dan información taurina nos vemos en la obligación de censar todo cuanto ocurre en las plazas y fuera de ellas con críticos, periodistas y fotógrafos propios. Si no lo hiciéramos, se perdería parte de la memoria colectiva del toreo contemporáneo a nosotros y hay un buen número de aficionados que desea estar al tanto de todo lo que ocurre en el planeta de los toros.

Eso no era necesario para El Ruedo o para Dígame porque en su época, todos los diarios y la radio daban toda la información taurina. Hoy no pasa eso. Aunque tenemos un programa de televisión de media hora a la semana, un programa de radio diario y varios periódicos que dedican en algún momento de la temporada espacio a los toros junto a otras revistas taurinas... se trata de una información 
fragmentaria. Ello hace necesario que una revista como la nuestra cense todo lo que ocurre en el toreo porque nadie más lo está haciendo y eso te quita espacio para hacer una revista más coherente con su periodicidad semanal.

No podemos decir que no analizamos porque sí lo hacemos en la opinión, pero tendríamos que hacer una revista que se centrara más en los aspectos más importantes de la semana y que se olvidara de los otros. Pero claro, esos otros no están reflejados en la prensa. Lo están en los portales de Internet, pero ahí no aparecen jerarquizados. Internet es un caos, un saco de noticias en donde se autodestruyen unas con otras, porque se valora tanto la nimiedad como lo importante, lo falso como lo verdadero... y claro, visto lo visto, nos ha tocado cumplir una misión informativa importante, porque no queda constancia en ningún medio escrito de cuanto acontece a lo largo de la temporada y nosotros, por una cuestión de conciencia, de ética, queremos darlo" (De Haro, 2009a, pp. 431-432).

No obstante, el estudio de la revista confirma que en los últimos años ha crecido considerablemente el número de trabajos que exponen en profundidad al lector los hechos más destacados de la actualidad taurina a través de géneros clásicos como el reportaje y la entrevista. En este aspecto también ha aumentado el de aquellos que se detienen en sucesos desconocidos para el gran público pero que concitan el interés de los aficionados como por ejemplo las cuestiones relacionadas con la crianza y manejo del toro de lidia, los distintos encastes (castas) presentes en la cabaña brava, el entramado empresarial de la Fiesta, la doma de los caballos de rejoneo o el circuito de las novilladas.

Como publicación especializada, 6TOROS6 ha intensificado también la interpretación de los hechos más sobresalientes de la actualidad taurina. A través de la crónica, el editorial o el artículo de opinión, los periodistas y colaboradores de la revista ofrecen su personal valoración de lo más granado de la realidad taurómaca. La crónica taurina, el género híbrido por excelencia y también el más genuinamente español, cobra auge en la revista a medida que ésta se acerca a la periodicidad semanal aunque está presente en 6TOROS6 desde su origen. La firme voluntad de estar presente en todos los escenarios, españoles o no, donde la Fiesta se desarrolla es perseguida por la revista desde su origen.

Esta idea de universalidad lleva a 6TOROS6 a cubrir informativamente los seriales taurinos más importantes gracias a una extensa red de corresponsales 15 en todos los países taurinos del mundo permitiendo al lector un seguimiento detallado de las actuaciones de los toreros y del juego del ganado a lo largo de toda la temporada taurina.

\subsection{El futuro de 6TOROS6}

En el actual contexto informativo, la competencia de los portales temáticos de información taurina ha motivado que la revista 6TOROS6 asuma el reto de profundizar aún más en el análisis del presente taurino sin descuidar el seguimiento de la actualidad del mundo de los toros. Por esta razón, el futuro inmediato de la 
revista pasa por fomentar los trabajos de corte reflexivo que aporten una visión contextualizada de la realidad taurómaca.

Además, 6TOROS6 idea materializar la edición de varios suplementos semanales, cuatro al mes, dedicados al toro, la historia del toreo, el rejoneo y el ocio, más concretamente: CAMPO BRAVO: dedicado al toro; EL RUEDO: con historias antiguas del toreo; EL REJONEO: dedicada al caballo y al mundo del rejoneo y TAUROVIAJES: una revista con la intencionalidad de la antigua Tauroguía ${ }^{15}$, pero mejorada. Según el director de la publicación, este proyecto se abordará paulatinamente "porque se necesita una inversión grande, más personal para la redacción, etc. Se necesitan especialistas en caballos de una especialidad, la del rejoneo, que cuenta con pocos y verdaderos profesionales que la conozcan en profundidad.

Se necesitan buenos fotógrafos porque hablamos de revistas especializadas donde la imagen es fundamental para vender, en algunos casos, un producto como es el caso de la revista TAUROVIAJES, se necesitan buenos relaciones públicas que contacten con las empresas relacionadas con el sector de la hostelería o la moda, etc., periodistas especializados en cada disciplina... y eso es muy difícil de reunir y sobre todo muy caro de costear... Pero esa es la idea, aunque iremos poco a poco. EL REJONEO y TAUROVIAJES deberían salir primero y muy probablemente serán las revistas que en el momento que nos reporten rentabilidad puedan sustentar a las otras dos, la dedicada al toro y a la historia del toreo, dos publicaciones que tienen muy difícil financiación. Entonces, la colección de 6TOROS6 será completamente apasionante" (De Haro, 2009, pp. 434-435)

El grupo editorial que hace posible que 6TOROS6 esté presente cada semana a pie de kiosco también planea incrementar los títulos de su Serie Oro, un catálogo de volúmenes monográficos dedicados a los intérpretes más destacados del toreo contemporáneo que persigue ahondar en las claves de la tauromaquia de nuestro tiempo y que ha supuesto un nuevo hito en la vida de la publicación ${ }^{16}$.

\section{CONCLUSIONES}

El estudio de la historia del periodismo nos permite ejemplificar sobradamente el ejercicio de continua adaptación desarrollado por los medios impresos para garantizar su supervivencia en el complejo panorama mediático de cada época. 6TOROS6 no ha sido la excepción. El análisis diacrónico de esta publicación demuestra que, sin alterar su filosofía editorial inicial, los contenidos de la revista han variado en función de la atención que otros soportes informativos han prestado al mundo de los toros a lo largo del tiempo. Si en los momentos inmediatos a su nacimiento la revista acometió

\footnotetext{
15 es el nombre de un pequeño suplemento editado por la revista en sus primeros años y ofrecido a los lectores semanalmente que contenía información de interés para el aficionado que se desplazaba a los seriales taurinos más importantes por contener información relativa a hoteles, restaurantes, exposiciones, museos, etc. de cada localidad. Este cuadernillo que se vendía conjunta e inseparablemente con la revista es el germen de la nueva revista que el director planea editar

16 Hasta la fecha se han publicado cinco ejemplares, los dedicados a Morante de la Puebla (2007), José Tomás (2008), "El J uli" (2008), Miguel Ángel Perera (2009) y Pablo Hermoso de Mendoza (2009).
} 
una función analítica en contraposición a la información de más estricta actualidad ofrecida por la prensa diaria, la radio o la televisión, a medida que el eco mediático de la Fiesta fue menor en estos soportes, 6TOROS6 optó - a finales de su primera década de vida - por incrementar el espacio dedicado a testimoniar el presente taurino de España, Francia, Portugal y los países taurinos de América.

De igual modo, el asentamiento de los portales taurinos en Internet ha motivado un cambio de estrategia en la trayectoria evolutiva de la publicación objeto de nuestro estudio. A comienzos del año 2000, la llegada de Internet supuso un revulsivo para la información taurina. El éxito de los portales temáticos especializados puso de relieve la viabilidad de este novísimo soporte para la implantación de un modelo de periodismo sustentado básicamente en la información de actualidad y la participación de los usuarios. El portal www.burladero.com se alzó pronto en el medio de información taurina líder en Internet por ofrecer a los usuarios amplia información de actualidad taurina completamente gratuita. Este modelo, que lógicamente alcanzó de forma inmediata gran popularidad entre aficionados y profesionales del sector, obligó a 6TOROS6 a plegarse a los nuevos modos de los nuevos medios. Por esta razón, en los últimos años es palpable su esfuerzo por ofrecer una información mucho más analítica y reflexiva que la de etapas precedentes, consciente de que la información de más estricta actualidad taurina ha encontrado en la Red un magnífico ruedo para su difusión.

\section{REFERENCIAS}

Aguado, P. (2000). Río revuelto. 6TOROS6, (298).

Aguado, P. (2008). 6Toros6 renueva su apariencia y su diseño de cara a la nueva temporada, Consulatdo el 16 de Marzo de 2008, Disponible en:

www.burladero.com/noticias/000358/6toros6/renueva/apariencia/cara/nueva/tempora $\underline{\text { da }}$

De Haro de San Mateo, M. V. (2010). Un hito en la historia del periodismo. Las 'normas de estilo' de los portales taurinos en Internet [Versión electrónica]. Razón y Palabra, (74)

De Haro de San Mateo, M. V. (2009). 6TOROS6, revista de actualidad taurina. Tesis doctoral. Facultad de Ciencias de la Información de la Universidad Complutense de Madrid. Madrid.

De Haro de San Mateo, M. V. (2009). La información taurina cambia de tercio en el ruedo de Internet. En P. Fernández, (.Ed), Rompiendo moldes. Discurso, géneros e hibridación en el siglo XXI. Comunicación Social . Sevilla:Ediciones y Publicaciones.. 
De Haro de San Mateo, M. V. (2009, Marzo). Un ejemplo de realidad fragmentada: la información taurina en los medios de comunicación españoles. Vivat Academia, (109). Consultado el 20 de Marzo del 2010, Disponible en:

www.ucm.es/info/vivataca/numeros/n109/articulo.htm\#unejem

De Haro de San Mateo, M. V. (2006). Diez años de información taurina en Internet. Un nuevo modelo de periodismo taurino. En J. J, Fernando (Ed.), Análisis y propuestas en torno al periodismo digital. Huesca: Ayuntamiento de Huesca y Asociación de la Prensa de Aragón.

De Haro de San Mateo, M. V. (2004). Taurología, referente de las revistas culturales taurinas. En C. Sanz \& J. Sotelo \& A. L Rubio (Eds.), Prensa y Periodismo Especializado /I, (historia y realidad actual). Guadalajara: Editores del Henares.

De Haro de San Mateo, M. V. \& Pizarroso Quintero, A. (2003). Los Toros en la Red. En A. García Baquero \&, P. Romero (Eds.), Fiestas de Toros y Sociedad. Sevilla: Universidad de Sevilla.

De Haro de San Mateo, M. V. \& Pizarroso Quintero, A. (2002). Periodismo y mundo taurino en Internet. En J. J, Fernando, J. C Rueda. \& Sanz, C. (Eds.). Prensa y Periodismo Especializado (historia y realidad actual). Guadalajara: Ayuntamiento de Guadalajara.

Edo, C. (1999). Las revistas e Internet como soportes del periodismo especializado y la divulgación. Revista Estudios sobre el mensaje periodístico, (5).

Moncholl Chaparro, M. A. (2003). Burladero.com, la aventura de los toros en Internet. Madrid: Egartorre.

Moncholl Chaparro, M. A. (2007) Internet y el planeta de los toros. En Cossío (Ed.), Los Toros. Literatura y Periodismo, (8). Madrid: Espasa.

Romero de Solís, P. (2000). Las revistas culturales de toros en España. Taurología Revista de Estudios Taurinos, (12).

\section{María Verónica de Haro de San Mateo}

Doctora en Periodismo por la Universidad Complutense de Madrid, actualmente es profesora del departamento de Información y Documentación de la Facultad de Comunicación y Documentación de la Universidad de Murcia, donde imparte docencia en las asignaturas "Teoría e Historia del Periodismo" y "Fundamentos de la Información y la Comunicación". Sus principales líneas de investigación son el estudio de la Historia de la Comunicación Social y del Periodismo, temas sobre los que ha publicado libros y artículos académicos y defendido ponencias en congresos nacionales e internacionales. Forma parte de la Asociación de Historiadores de la Comunicación y de la Asociación Española de Investigadores en Comunicación. 